\title{
Analisis Pemakaian Bahan Bakar pada Mesin MAK 8M453 Unit 5 PLTD Telaga
}

\author{
Hendra Uloli 1), Jamal Darusalam Giu ${ }^{2)}$, Alifransi Sulaeman ${ }^{3)}$ \\ 1),2),3) Jurusan Teknik Industri, Fakultas Teknik, Universitas Negeri Gorontalo \\ email : hendra.uloli@ung.ac.id
}

\begin{abstract}
Abstrak
PLTD Telaga menggunakan mesin MAK 8M453 yang terdiri dari 10 unit untuk membangkitkan daya. Pengoprasian pada unit-unit tersebut bergantung pada beban yang dibutuhkan oleh konsumen terutama pada waktu beban puncak, mengingat PLTD Telaga bukan merupakan sumber suplai listrik utama di Gorontalo. Mesin MAK 8M453 yang berjumlah 10 unit tersebut hanya 4 unit yang aktif berproduksi yaitu unit 3, 4,5 dan 6 sisanya dalam keadaan rusak. Tujuan penelitian ini Mengetahui banyaknya konsumsi bahan bakar untuk motor diesel penggerak generator listrik merek MAK 8M453 unit 5 di PLTD Telaga berdasarkan teori perbandingan udara dan bahan bakar sesuai dengan temperatur udara (ruangan) setempat dan akan dibandingkan dengan konsumsi bahan bakar yang ada di lapangan. Hasil penelitian satu jam perbandingan udara dan bahan bakar berdasarkan teori adalah 201,86 Kg/jam atau sama dengan 228,623 Liter/jam. Sedangkan konsumsi bahan bakar pada kenyataanya yang digunakan pada mesin MAK 8M453 unit 5 PLTD Telaga adalah dalam satu jam produksi yaitu sebesar 421,478 L/jam dan perbandingan anatara konsumsi bahan bakar secara teoritis dan lapangan yaitu sebesar 1 : 1,8
\end{abstract}

Kata kunci: Bahan Bakar, Mesin MAK 8M453, PLTD

\begin{abstract}
Diesel power Plant in Telaga uses the MAK 8 M453 engine which consists of 10 units to generate power. Operation on these units depends on the load needed by consumers, especially at peak load times considering that the Telaga PLTD is not the main source of electricity supply in Gorontalo. Among The MAK 8 M453 machines, there are only 4 units which are active, namely unit 3, unit 4, unit 5 while the remaining 6 were damaged. The purpose of this study was to determine the amount of fuel consumption for MAK $8 M 453$ unit 5 electric generator motorized diesel generator in Telaga PLTD based on the theory of air and fuel comparisons ratio due to the local air temperature (room) and will be compared with fuel consumption in the field. Based on theory calculation the air and fuel comparisons ratio were $201.86 \mathrm{Kg} /$ hour or equal to 228.683 Liters / hour. Whereas the fuel consumption in fact used in the MAK 8M453 unit 5 engine Telaga PLTD is in one hour of production that is equal to 421,478 L / hour and the comparison between the fuel consumption theoretically and the field is equal to 1: 1,8
\end{abstract}

Keywords: Fuel Consumption, MAK 8 M453 engine, Diesel Power Plant

\section{Pendahuluan}

Motor diesel adalah jenis motor bakar torak yang biasanya disebut Motor Pembakaran Kompresi (Compression Ignition Engine). Pembakaran yang terjadi dalam ruang bakar dilakukan dengan cara menyemprotkan bahan bakar ke dalam silinder motor yang terisi dengan udara yang bertekanan dan bertemperatur tinggi, sebagai akibat dari proses kompresi. 
Pembangkit Listrik Tenaga Diesel (PLTD) Telaga adalah bagian dari unit pembangkitan dan penyediaan energi llistrik dari PT. PLN (Persero) Area Gorontalo. PT PLN (Persero) area Gorontalo merupakan Badan Usaha Milik Negara yang membawahi pembangkitan dan penyediaan energi listrik bagi masyarakat Gorontalo, khususnya pada penyediaan tenaga listrik untuk mendukung aktivitas masyarakat.

Mesin merupakan salah satu alat produksi yang mempunyai peranan yang sangat penting dalam produktivitas di dalam suatu organisasi atau perusahaan, dimana suatu produktivitas ada yang sangat bergantung pada mesin (Hendrik, 2011). PT PLN (persero) Area Gorontalo mempunyai tugas sebagai penyedia tenaga listrik untuk kepentingan umum, upaya untuk penyediaan tenaga listrik yang dapat memenuhi kebutuhan konsumen. Baik itu kebutuhan listrik pada rumah tangga, industri, perkantoran, sosial, bisnis, maupun penerangan jalan.

PLTD Telaga menggunakan mesin MAK 8M453 yang terdiri dari 10 unit untuk membangkitkan daya. Pengoprasian pada unit-unit tersebut bergantung pada beban yang dibutuhkan oleh konsumen terutama pada waktu beban puncak, mengingat PLTD Telaga bukan merupakan sumber suplai listrik utama di Gorontalo. Mesin MAK 8M453 yang berjumlah 10 unit tersebut hanya 4 unit yang aktif berproduksi yaitu unit 3, 4,5 dan 6 sisanya dalam keadaan rusak.

Kelancaran dari pelaksanaan proses produksi listrik pada PLTD Telaga merupakan suatu hal pokok yang harus dicapai. Fungsi yang memegang peranan yang sangat penting dalam menjamin kelancaran pelaksanaan kegiatan produksi adalah performa mesin. Salah satu parameter untuk menilai performa mesin adalah konsumsi bahan bakar. Oleh sebab itu, penulis merasa perlu untuk mengetahui konsumsi bahan bakar pada mesin MAK 8M453 Pembangkit Listrik Tenaga Diesel (PLTD) Telaga berdasarkan perhitungan perbandingan kompresi bahan bakar secara teoritis dan akan dibandingkan dengan konsumsi bahan bakar yanga ada dilapangan.

Penelitian ini dilakukan pada mesin MAK 8M453 unit 5 untuk mewakili unit-unit lainnya, karena kesepuluh unit mesin ini adalah mesin yang sama, juga mesin unit 5 adalah salah satu yang sekarang beroprasi. Alasan lainya yang paling penting adalah penulis memiliki data paling lengkap tentang data konsumsi bahan bakarnya.

\section{Tinjauan Pustaka}

\section{Sistem Bahan Bakar}

Pada sistem bahan bakar mesin Diesel, pompa pengalir menghisap bahan bakar dari tangki bahan bakar. Bahan bakar disaring oleh saringan bahan bakar dan kandungan air yang terdapat pada bahan bakar dipisahkan oleh fuel sedimenter sebelum dialirkan ke pompa injeksi bahan bakar. Rakitan pompa injeksi terdiri dari 
pompa injeksi, governor dan pompa pengalir. Dengan digerakkan oleh mesin, pompa injeksi menekan bahan bakar dan dialirkan ke nosel injeksi, dan selanjutnya diinjeksikan ke dalam silinder menurut urutan pengapian. Untuk penyalurannya sampai pada ruang bakar dengan suatu kondisi tertentu diperlukan suatu sistem bahan bakar (Ahmad Yani: ISSN 2301-6663).

Fungsi system bahan bakar :

1. Mengatomkan atau mengabutkan bahan bakar agar mudah bercampur merata dengan udara sehingga mudah terbakar.

2. Mengatur jumlah bahan bakar yang sama pada setiap pemasukan disetiap silinder pada setiap kebutuhan sehingga tenaga ( power ) setiap silinder adalah sama.

3. Mengatur saat mulai penyemprotan dan lamanya penyemprotan.

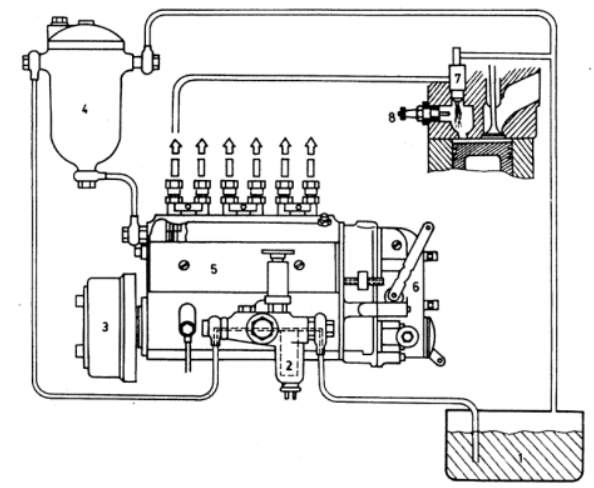

Gambar 5. Sistem Bahan Bakar 6 Silinder

\section{Bahan Bakar Motor Diesel}

Defenisi bahan bakar diesel (solar) - product hasil industri migas terbagi dalam beragam jenis jenis dengan ciri-ciri dan karakter yang tidak sama, salahnya ialah fraksi diesel. Solar yaitu satu diantara jenis bahan bakar yang dibuat dari sistem pemrosesan minyak bumi, pada intinya minyak mentah dipisahkan fraksi-fraksinya pada sistem destilasi hingga dibuat fraksi solar dengan titik didih $250^{\circ} \mathrm{C}$ hingga $300^{\circ} \mathrm{C}$. berikut jenis bahan bakar motor diesel. High Speed Diesel (HSD), Marine Fuel Oil (MFO), Minyak Bakar, d. Industrial Diesel Oil (IDO), Biodiesel, Diesel Permorma Tinggi (Eko Widagdo.2013)

\section{Perbandingan Udara -Bahan Bakar Teoritis (Stoikiometri).}

Bahan bakar motor diesel adalah senyawa hidrokarbon yang terjadi dari $86 \%$ berat $\mathrm{C}$ (Carbon) dan $14 \%$ berat $\mathrm{H}$ (Hidrogen). Berat atom $\mathrm{C}$ adalah 12 dan berat atom $\mathrm{H}$ adalah 1,008 (Subando Muksin : 2014).

Persamaan pembakaran :

$$
\begin{aligned}
& \mathrm{C}+\mathrm{O} 2 \mathrm{CO} 2 \ldots \ldots \\
& 2 \mathrm{H} 2+\mathrm{O} 22 \mathrm{H} 2 \mathrm{O}
\end{aligned}
$$




\section{Metode}

\section{Tempat Penelitian}

PT. PLN (Persero) Area Gorontalo pada mesin MAK 8M453 Unit 5 PLTD Telga.

\section{Prosedur Penelitian}

Langkah-langkah yang akan ditempuh dalam penelitian ini meliputi:

\section{Studi Kepustakaan}

Studi kepustakaan dilakukan dengan mempelajari serta mengutip teori dan data sekunder dari referensi yang berkaitan

\section{Pengolahan dan analisis data}

Pengolahan data dilakukan dengan menggnakan excel untuk menganalisis konsumsi bahan bakar pada mesin MAK 8M453 PLTD Gelaga guns mengetahui berapa banayak bahan bakar yang digunaka dalam 1 jam produksi.

\section{HASIL DAN PEMBAHASAN}

Dalam penelitian ini tentunya harus mengetahui data berupa spesifikasi mesin MAK 8M453. Data mesin MAK 8M453 tersebut adalah sebagai berikut:

\begin{tabular}{|c|c|}
\hline Merk/Type & : MAK/ 8M 453 \\
\hline Nomor Seri & : 27184 \\
\hline Daya Efektif & : $2860 \mathrm{~kW}$. \\
\hline Diameter Silinder & : $320 \mathrm{~mm}$ \\
\hline Panjang Langkah Torak & : $420 \mathrm{~mm}$ \\
\hline Urutan Penyalaan & : 1-3-2-5-8-6-7- 4 \\
\hline Putaran Motor & : 600 RPM \\
\hline Perbandingan Kompresi & $18: 1$ \\
\hline Jumlah Silinder & $: 8(1-$ line $)$ \\
\hline Digunakan untuk & : Penggerak Generator \\
\hline Negara Pembuat & : Germany \\
\hline Bahan Bakar & : SOLAR \\
\hline \multicolumn{2}{|c|}{ Katup isap membuka (BTDC) 570} \\
\hline \multicolumn{2}{|c|}{ Katup isap menutup (ABDC) 450} \\
\hline \multicolumn{2}{|c|}{ Katup buang membuka (BBDC) 560} \\
\hline \multicolumn{2}{|c|}{ Katup buang menutup (ATDC) 510} \\
\hline
\end{tabular}

\section{Kebutuhan Udara Untuk Pembakaran}

1. Bahan bakar sebagian besar terdiri dari $\mathrm{C}_{14}-\mathrm{H}_{30}$, yang mana :

$$
\mathrm{C}_{14} \mathrm{H}_{30}+\mathrm{O}_{2}+\mathrm{N}_{2} \mathrm{CO}_{2}+\mathrm{H}_{2} \mathrm{O}+\mathrm{N}_{2}
$$

udara Pembakaran sempurna $\mathrm{H}$ menjadi $\mathrm{H}_{2} \mathrm{O}$ adalah :

$$
\mathrm{H}_{30} \quad 15 \mathrm{H}_{2} \mathrm{O}
$$


2. Pembakaran sempurna $\mathrm{C}$ menjadi $\mathrm{CO}_{2}$ adalah

$$
\mathrm{C}_{14} 14 \mathrm{CO}_{2}
$$

3. Reaksi Oksigen

$$
21,5 \mathrm{O}_{2} \longleftarrow 14 \mathrm{CO}_{2}+15 \mathrm{H}_{2} \mathrm{O}
$$

Diudara setiap 1 mole oksigen bersamaan dengan 3,76 mole€ nitrogen.

$$
21,5(3,76) \mathrm{N}_{2} \longrightarrow 0,84 \mathrm{~N}_{2}
$$

Maka dengan demikian didapatkan persamaan reaksi sebagai berikut:

$$
\mathrm{C} 14+\mathrm{H} 30+12,5 \mathrm{O} 2+80,84 \mathrm{~N} 2 \longrightarrow 14 \mathrm{CO} 2+15 \mathrm{H} 2 \mathrm{O}+80,84 \mathrm{~N} 2
$$

Maka dengan hasi persamaan reaksi diatas dapat kita hitung antara perbandingan jumlah udara dan jumlah bahan bakar sebagai berikut:

$$
\begin{gathered}
\frac{\text { jumlah udara }}{\text { jumlah bahan bakar }}=\frac{(21,580,84)+(29)}{14(12)+30} \\
=\frac{2967,86}{198} \\
=14,98
\end{gathered}
$$

\section{Pemakaian Udara Pada Motor}

Dengan mengetahui data motor dan data supercharging maka pemakaian udara pada motor dapat dihitung sebagai berikut : Tekanan Udara Pada Awal Pengisian.

Tekanan udara pada awal pengisian untuk motor dengan supercharging dapat diperoleh dengan rumus berikut :

\section{Tekanan udara Sebelum Masuk Ke Super Charger (Po')}

$$
\mathrm{Po}^{\prime}=\mathrm{Po}-\mathrm{Po}_{1}, \mathrm{Kg} / \mathrm{Cm}_{2} \text {. }
$$

dimana :

$$
\begin{aligned}
\text { Po } & =\text { Tekanan udara luar } \\
& =1 \text { atm abs } \\
& =\text { Kerugian tekanan pada pipa pemasukan sebelum supercharger } \\
& =(0,03-0,05) \cdot \text { Po } \\
& =0,04 . \text { Po (diambil) } \\
\text { maka : Po' } & =\text { Po }-(0,04 . \text { Po }) \\
& =1-(0,04 \times 1) \\
& =0,96 \mathrm{Kg} / \mathrm{Cm}^{2} .
\end{aligned}
$$




\section{Temperatur Udara Sesudah Supercharger}

( $\left.T_{\text {sup }}\right)$, dapat dihitung dengan menggunakan persamaan berikut :

$$
\begin{aligned}
\mathrm{T}_{\text {sup }} & =\mathrm{T}_{0} \times\left[\frac{P_{\text {sup }}}{P_{0}}\right]^{\frac{n-1}{n}},{ }^{\circ} \mathrm{K} . \\
\mathrm{T} \text { sup } & =308 \times\left[\frac{1,27}{0,96}\right]^{\frac{1,85-1}{1,85}} \\
\mathrm{~T}_{\text {sup }} & =308 \times 1,1371 \\
\mathrm{~T}_{\text {sup }} & =350,251{ }^{\circ} \mathrm{k}
\end{aligned}
$$

dimana :

$$
\begin{aligned}
\text { To } & =\text { Temperatur udara luar }\left(35^{\circ} \mathrm{C}\right) \\
& =(273+35) \\
& =308{ }^{\circ} \mathrm{K} \\
\mathrm{P}_{\text {sup }} & =\text { Tekanan sesudah supercharger } \\
& =(1,20-1,35) \text { atm abs (putaran rendah) } \\
& =1,27 \mathrm{~atm} \text { abs (diambil) } \\
& =1,20 \times 1 \\
& =1,27 \mathrm{Kg} / \mathrm{Cm}^{2} \\
\mathrm{n} & =\text { Eksponen polytropik udara atmosfir } \\
& =(1,7-2,0) \text { untuk centrifugal supercharger } \\
& =1,85 \text { (diambil) }
\end{aligned}
$$

\section{Tekanan Udara Pada Awal Langkah Kompresi (Pa).}

Tekanan udara pada awal langkah kompresi atau akhir langkah pengisian silinder dapat ditentukan sebagai berikut :

$$
\begin{aligned}
\mathrm{Pa} & =(0,90,95) \text { Psup, } \mathrm{Kg} / \mathrm{Cm}^{2} . \\
& =0,925 \text { Psup (dipilih) } \\
& =0,925 \times 1,27 \\
\mathrm{~Pa} & =1,174 \mathrm{~kg} / \mathrm{cm}^{2}
\end{aligned}
$$

\section{Temperatur Awal Pada Langkah Kompresi $\left(\mathrm{T}_{\mathrm{a}}\right)$}

Temperatur udara di dalam silinder pada awal langkah kompresi dihitung sebagai berikut:

dimana :

$$
\mathrm{T}_{\mathrm{a}}=\frac{\mathrm{T}_{\text {sup }}+\mathrm{t}_{\mathrm{w}}+\gamma_{\mathrm{r}} \mathrm{T}_{\mathrm{r}}}{1+\gamma_{\mathrm{r}}}
$$

$$
\begin{aligned}
r= & \text { Koefisien gas residu } \\
= & (0,03-0,04) \text { untuk motor empat tak }=0,035 \text { (diambil) } \\
t w= & \text { Kenaikan temperatur udara didalam silinder karena bersentuhan dengan } \\
& \text { saluran }
\end{aligned}
$$


pengisian, katup, kepala silinder, kepala torak, dan dinding silinder yang panas

$=\left(10^{\circ} \mathrm{C}-15^{\circ} \mathrm{C}\right)$ untuk motor 4 langkah dengan supercaharger

$=12,5^{\circ} \mathrm{C}$ (diambil)

$\mathrm{T}_{\mathrm{r}}=$ Temperatur gas residu

$=356^{\circ} \mathrm{C}$

$=629^{\circ} \mathrm{K}$ (berdasarkan data operasi mesin)

Maka :

$$
\begin{aligned}
\mathrm{T}_{\mathrm{a}} & =\frac{350,251+12,5+(0,035 \times 629)}{1+0,035} \\
& =371,755^{\mathrm{O}} \mathrm{K} .
\end{aligned}
$$

\section{Efisiensi Pengisian $\left(\mathrm{D}_{\mathrm{ch}}\right)$}

Efisiensi pengisian dihitung sebagai berikut :

$$
\begin{gathered}
\eta_{\text {ch }}=\frac{\varepsilon}{\varepsilon-1} \frac{\mathrm{P}_{\mathrm{a}}}{\mathrm{P}_{\text {sap }}} \frac{\mathrm{T}_{\text {sup }}}{\mathrm{T}_{\mathrm{a}}\left(1+\gamma_{\mathrm{r}}\right)} \\
\mathrm{N} c h=\frac{15,5 \times 1,747 \times 350,251}{(15,5-1) \times 1,27 \times 371,755 \times(1+0,035)} \\
\mathrm{D}_{\mathrm{ch}}=1,338
\end{gathered}
$$

\section{Jumlah Udara Yang Tertampung Di Dalam Silinder}

Jumlah udara segar (Vu.c) yang berada didalam silinder motor pada awal langkah kompresi dapat dihitung dengan menggunakan rumus berikut:

$$
\text { Vu.c }=\mathrm{Vs}+\mathrm{Vc}-\mathrm{Vsc}, \mathrm{m}^{3} \text {. }
$$

dimana :

Vs - Volume langkah torak, $\mathrm{Cm}^{3}$.

$\mathrm{Vs}=14 . \mathrm{D}^{2} . \mathrm{S}$.

$$
=3,14 / 4 \cdot 0.32^{2} \cdot 0,42 \cdot=0,033 \mathrm{~m}^{3}
$$

dimana :

$\mathrm{D}$ - diameter silinder motor $=0,32 \mathrm{~m}$

$S$ - panjang langkah torak $=0,42 \mathrm{~m}$

$\mathrm{V}_{\mathrm{c}}=$ Volume akhir langkah kompresi, $\mathrm{m}^{3}$.

dimana :

- perbandingan kompresi yaitu $(12-19)$

$=15,5$ (diambi)

Vs.c - volume silinder sebelum terjadi kompresi, yaitu volume pada saat torak bergerak dari TMB sampai saat terjadi kompresi dimana katup isap mulai tertutup ( $45^{\circ}$ putaran engkol setelah TMB), $\mathrm{m}^{3}$. 


$$
\text { Vs.c }=\pi / 4 \cdot D^{2} \cdot(r-r \cdot \cos \theta), \mathrm{m}^{3} .
$$

TMA $=0,785 \times 0,32^{2} \times(0,21-0,21 \cdot \cos 45)$.

$\mathrm{TMB}=0,005 \mathrm{~m}^{3}$.

dimana : $r$ - radius engkol

$$
\begin{aligned}
& =S / 2=0,42 / 2 \\
& =0,21 \mathrm{~m} .
\end{aligned}
$$

- sudut antara pipi engkol dengan $\mathrm{TMB}=45^{\circ}$

Dimana: $\frac{V a}{\varepsilon} \frac{V c+V s}{V c}$

Ket : Perbandingan Konpresi

Vs - Volume Langka Torak, $\mathrm{mm}^{3} \quad \mathrm{Vc}$ - Volume Konpresi, $\mathrm{mm}^{3}$

Va - Volume Total, $\mathrm{mm}^{3}$

Maka : Vc $=\frac{V s}{\varepsilon-1}$

$$
\begin{aligned}
& =\frac{0,033}{15,5-1} \\
& =0,002 \mathrm{~mm}^{3}
\end{aligned}
$$

Jadi pada awal langkah kompresi, jumlah udara yang dapat tertampung didalam satu silinder motor adalah :

$$
\begin{aligned}
\text { Vu.c } & =0,033+0,002-0,005, \mathrm{~m}^{3} . \\
& =0,036-0,005 \\
& =0,031 \mathrm{~m}^{3}
\end{aligned}
$$

Berat udara pada awal langkah kompresi dalam satu silinder motor dapat dihitung sebagai berikut:

$$
\begin{aligned}
\mathrm{G}_{\text {berat udara awal langkah kompresi dalam1 silinder }} & =\operatorname{VuC} X \operatorname{Pa} X \frac{273+0}{273+T a} \times 1,3 \\
\mathrm{G}_{\text {berat udara awal langkah kompresi dalam1 silinder }} & =0,031 X 1,174 X \frac{273+0}{273+371,755} \times 1,3 \\
& =\frac{\mathbf{9 , 9 5 1}}{\mathbf{6 4 4 , 7 5 5}} \times 1,3 \\
& =0,015 \times 1,3 \\
& =0,020 \mathrm{Kg} .
\end{aligned}
$$

Dimana :

$$
\begin{aligned}
\mathrm{Pa} & =\text { tekanan udara pada awal langkah kompresi } \\
& =1,174 \mathrm{Kg} / \mathrm{Cm}^{2} .
\end{aligned}
$$

Ta - temperatur udara pada awal langkah kompresi

$=371,755^{\circ} \mathrm{K}$. 
Jadi berat udara untuk 8 buah silinder pada satusiklus kerja motor adalah :

$$
\begin{aligned}
\mathrm{G}_{\text {udara }} & =8 \times 0,020 \mathrm{Kg} . \\
& =0,16 \mathrm{Kg} .
\end{aligned}
$$

Dengan demikian untuk satu menit (600 putaran), motor memerlukan udara sebanyak :

$$
\begin{aligned}
\text { Gudara per menit }_{\text {t }} & =0,5 \times 600 \times 0,160 \\
& =48,155 \mathrm{Kg}
\end{aligned}
$$

\section{Perhitungan Pemakaian Bahan Bakar Menurut Pemakaian Udara Motor.}

Dari perhitungan sebelumnya, terlihat bahwa untuk pembakaran sempurna $1 \mathrm{Kg}$ bahan bakar solar, dibutuhkan $14,98 \mathrm{Kg}$ udara segar.

Jadi dengan berat udara pada awal langkah kompresi untuk satu siklus kerja motor sebesar $0,16 \mathrm{Kg}$, maka banyaknya bahan bakar solar yang dibutuhkan adalah sebesar

$$
\begin{aligned}
\mathrm{G}_{\text {solar per siklus }} & =0,16: 14,98 \mathrm{~kg} \\
& =0,010 \mathrm{Kg} . \\
& =0,011 \mathrm{~L} / \text { siklus }
\end{aligned}
$$

Dengan demikian bila motor dioperasikan dengan putaran kontinu /beban kontinu (600 rpm), maka motor akan menggunakan bahan bakar selama 1 menit adalah sebanyak :

$$
\begin{aligned}
\mathrm{G}_{\text {solar per menit }} & =0,5 \times 600 \times 0,010 \\
& =3 \mathrm{Kg} . \\
& =3,381 \mathrm{~L} / \text { menit }
\end{aligned}
$$

Jadi dalam satu jam, motor dioperasikan dengan putaran kontinu $600 \mathrm{rpm}$, menggunakan bahan bakar sebanyak :

$$
\begin{aligned}
\mathrm{G}_{\text {solar per jam }} & =60 \times 3,381 \\
& =202,86 \mathrm{Kg} . \\
1 \mathrm{~kg} & =1,127 \mathrm{~L}
\end{aligned}
$$

Maka : $\mathrm{G}_{\text {solar per jam }}=202,86 \times 1,127$

$$
=228,623 \mathrm{~L} / \mathrm{jam}
$$

Dalam satu detik motor menggunakan bahan bakar solar sebanyak :

$$
\begin{aligned}
\mathrm{G}_{\text {solar per detik }} & =\mathrm{G}_{\text {solar per jam }: 3600} \\
& =202,86: 3600 \\
& =0,056 \mathrm{Kg} \\
& =0,063 \mathrm{~L} / \mathrm{dtk}
\end{aligned}
$$

Nilai kalori atau nilai panas bahan bakar solar sebanyak $1 \mathrm{Kg}$ adalah sebesar $\mathrm{HI}=$ 10100 Kcal (Muksin:2014). Jadi banyaknya panas yang dihasilkan oleh motor akibat 
pembakaran bahan bakar dan udara di dalam silinder motor selama satu detik (Qmotor per deti) adalah

$$
\begin{aligned}
Q_{\text {motor per detik }} & =\mathrm{G} \text { Solar per detik } \times \mathrm{H}_{\mathrm{I}} \\
& =0,056 \times 10100 \\
& =565,6 \mathrm{Kcal} . \\
1 \mathrm{Kcal} & =427 \mathrm{Kg} \cdot \mathrm{m} \\
1 \mathrm{PK} & =75 \mathrm{Kg} \cdot \mathrm{m} / \text { detik }
\end{aligned}
$$

maka 565,6 Kcal akan menghasilkan daya motor sebesar :

$$
\begin{aligned}
\mathrm{Ni} & =\left(Q_{\text {motor per detik } x} 427 \mathrm{Kg} \cdot \mathrm{m}\right): 75 \mathrm{Kg} \cdot \mathrm{m} / \text { detik } \\
& =(565,6 \times 427): 75 \\
& =3220,149 \mathrm{PK} .
\end{aligned}
$$

\section{Konsumsi Bahan Bakar Mesin MAK 8M453 Dilapangan}

Perhitungan rata-rata konsumsi bahan bakar solar mesin MAK 8M453 unit 5 adalah sebagai berikut :

$$
\begin{aligned}
G_{\text {total kosumsi solar per } 30 \text { menit }} & =9694 \mathrm{~L} \\
\text { Grata-rata kosumsi solar per } 30 \text { menit } & =\frac{\text { Gtotal kosumsi solar per 30 menit }}{N} \\
\text { Grata-rata kosumsi solar per } 30 \text { menit } & =\frac{9694}{46} \\
G_{\text {rata-rata kosumsi solar per } 30 \text { menit }} & =210,739 \mathrm{~L} / \text { menit } \\
\text { Ket : N }- \text { Jumlah Data } & =46 \\
\text { G }_{\text {solar rata-rata Per } 1 \text { Jam }} & =G_{\text {rata-rata kosumsi solar per } 30 \text { menit }} \times 2 \\
& =210,739 \mathrm{~L} \times 2 \\
& =421,478 \mathrm{~L} / \mathrm{jam}
\end{aligned}
$$

\section{Pembahasan}

Analisis bahan bakar yang didapatkan dari konsumsi bahan bakar berdasarkan kompresi pada mesin MAK 8M453 unit 5 PLTD Telaga adalah dalam satu jam perbandingan udara dan bahan bakar berdasarkan teori adalah 201,86 Kg/jam atau sama dengan 228,623 Liter/jam. Sedangkan konsumsi bahan bakar pada kenyataanya yang digunakan pada mesin MAK 8M453 unit 5 PLTD Telaga adalah dalam satu jam produksi yaitu sebesar 421,478 L/jam. Perbandingan anatara konsumsi bahan bakar secara teoritis dan lapangan yaitu sebesar $1: 1,8$. Penggunaan bahan bakar pada mesin MAK 8M453 unit 5 PLTD Telaga tentunya sudah tidak maksimal lagi berdasarkan teoritis dalam penggunaan bahan bakar perjam. Penggunaan konsumsi bahan bakar yang berlebihan pada mesin MAK 8M453 unit 5 PLTD Telaga kemungkinan besar disebabkan oleh beberapa hal anatara lain yaitu, temperatur udara luar yang berada disekitar motor diesel penggerak generator dengan merek MAK 8M453 Unit 5 di PLTD Telaga Gorontalo 
yang tinggi, kemudian Temperatur pendingin udara setelah turbo charging (air cooler) sangat tinggi, pipa saluran bahan bakar ada yang mengalami kebocoran dan pemborosan pemakaian bahan bakar terjadi pada putaran mesin maksimum sedangkan umur mesin sudah relatif tua.

\section{Kesimpulan}

Dari hasil pembahasan pada bab sebelumnya maka penulisan menarik sebuah kesimpulan sebagai berikut :

1. Banyaknya bahan bakar solar yang dikonsumsi oleh motor diesel generator listrik merek MAK 8M453 Unit 5 dalam satu jam berdasarkan perbandingan udara dan bahan bakar adalah 201,86 Kg atau sama dengan 228,623 liter.

2. Banyaknya bahan bakar yang dikonsumsi oleh motor diesel tersebut menurut data yang diperoleh di lapangan selama 0,5 jam pengoperasian adalah 214 liter. Maka dalam 1 jam produksi pemakain bahan bakar adalah 428 liter.

\section{Daftar Pustaka}

Ahmad Yani.2015.Perencanaan Pemanfaatan Marine Fuel Oil (MFO) Sebagai Bahan Bakar Engine Diesel MAK.Jurnal TURBO Volume 4, No. 1, (https://ojs.ummetro.ac.id/index.php/turbo/article/ di akses 12 Maret 2018)

Eko Widagdo.2013. Optimasi Pola Pembebanan Daya Mesin Pembangkit Listrik Diesel SWD 16 TM 410 Terhadap Efisiensi Konsumsi Bahan Bakar.Jurnal. ELKHA Vol.5, No 2, Oktober 2013

Hendrik.2011.Analisis Perawatan (Maintenance) Mesin Pembangkit Listrik Tenaga Diesel (PLTD) Pada PT.PLN (Persero Cabang Rangat Wilayah Riau di Desa Kota Lama Kabupaten Inhu.Skripsi.Universitas Negeri Sultan Syarif Kasim Riau.

Subando Musksin. 2014.Kajian Pemakaian Bahan Bakar Pada Motor Diese Generator MAK di PLTD Gunung Patti Semarang Jawa Tengah.Jurnal. Teknologi, Volume 11 Nomor 2, 2014; 2030 - 2038 